\title{
Marcadores discursivos y español coloquial en las redes sociales
}

\section{Discursive markers and informal Spanish in social network sites}

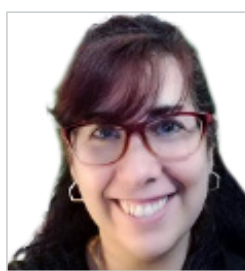

Ana Pano Alamán. Titular de lengua y lingüística española en la Universidad de Bolonia. Sus áreas de investigación son el análisis lingüístico-pragmático del discurso digital y de los discursos político y periodístico en español. Ha publicado diversas monografías y artículos en revistas nacionales e internacionales sobre el impacto del paradigma digital en los discursos mediático y político. Ha impartido conferencias sobre estos temas en distintas universidades. Ha sido miembro de la Junta directiva de la Asociación internacional de Estudios de Discurso y Sociedad y forma parte de grupos de investigación y proyectos dedicados al estudio de la lengua en los medios de comunicación.

Universidad de Bolonia, Italia

ana.pano@unibo.it

ORCID: 0000-0003-3652-8694

Recibido: 30/06/2020 - Aceptado: 19/10/2020

\section{Resumen:}

En este artículo se presentan los resultados de un análisis cuantitativo y cualitativo de la presencia y funciones de los marcadores discursivos del español en Facebook, Twitter y YouTube. Los objetivos de esta investigación son identificar los principales usos de estas partículas en las redes sociales y determinar en qué medida relacionan el discurso en estas plataformas con la modalidad oral coloquial de la lengua. El análisis de un corpus de tuits y comentarios confirma que los más utilizados por los usuarios son los conectores contraargumentativo pero y aditivos además, encima e incluso, el comentador pues y los conversacionales claro, hombre, bueno y vamos con función interactiva reactiva. Estos marcadores suelen emplearse para argumentar la propia opinión y negociar la interacción en espacios en los que predomina la polémica.

\section{Palabras clave:}

Redes sociales virtuales; marcadores discursivos; registro coloquial; argumentación; interacción.
Received: 30/06/2020 - Accepted: 19/10/2020

\section{Abstract:}

This paper presents the results of a quantitative and qualitative analysis of the incidence and the functions of Spanish discourse markers in Facebook, Twitter, and YouTube. The aims of this study are identifying the main uses of these particles in social network sites and outlining the possible connection between the use of these markers and the informal oral register of Spanish in tweets and commemnts in these platforms. The analysis of a corpus of messages confirms that the most frequently used are the counterargumentative connectors like pero, the additives además, encima $\mathrm{e}$ incluso, the commentator pues, and the interactional claro, hombre, bueno, vamos y ieh? Such markers are mainly employed in order to provide valid arguments and negotiate interaction within spaces where conflict predominates.

\section{Keywords:}

Social network sites; discursive markers; informal register; argumentation; interaction.

\section{Introducción}

El interés sobre el discurso digital en español ha aumentado en los últimos años como demuestran las investigaciones realizadas desde enfoques lingüísticos, sociolingüísticos, discursivos y pragmáticos (Mancera Rueda y Pano Alamán, 2013; Estrada Arráez y de Benito Moreno, 2016; Giammatteo et al., 2017; Robles Ávila y Moreno Ortiz, 2019). Hoy en día,

Cómo citar este artículo:

Pano Alamán, A. (2020). Marcadores discursivos y español coloquial en las redes sociales. Doxa Comunicación, 31, pp. 381-401. https://doi.org/10.31921/doxacom.n31a19 
la mayor parte de los estudios se centra en la interacción en las redes sociales virtuales, asumiendo que el contexto tecnológico y sociosituacional del intercambio comunicativo y las condiciones de producción y recepción de los mensajes determinan en gran parte el registro lingüístico empleado por los hablantes cuando interactúan en esas plataformas. Desde esta perspectiva, se afirma que la mayor parte de los mensajes que se publican cotidianamente en Facebook o Twitter se sitúa en el polo de la inmediatez comunicativa (Koch y Oesterreicher 2007 [1990]), por lo que dichos mensajes presentan numerosas manifestaciones de elementos lingüísticos prototípicos de la modalidad oral coloquial del español (Briz Gómez, 2014), como son la brevedad (Cantamutto y Vela Delfa, 2020) o la abundancia de neologismos y expresiones dialectales (Mancera Rueda y Pano Alamán, 2013).

A pesar de que en algunos de los estudios citados se menciona la presencia de los marcadores discursivos, su análisis se ha limitado a pocas investigaciones sobre el discurso político español y argentino en Twitter (Loredo y Picone, 2012; Pano Alamán y Mancera Rueda, 2014; Padilla Herrada, 2016). A partir de estas consideraciones, este trabajo tiene como objetivo contribuir a colmar ese vacío por medio de un análisis cuantitativo-cualitativo lingüístico-pragmático de los marcadores discursivos empleados con mayor frecuencia en Facebook, Twitter y YouTube. El estudio pretende también reflexionar sobre la posible relación entre el uso de determinados marcadores y el registro coloquial que se impone, en distintos grados, en el discurso de las redes sociales, un discurso marcado generalmente por la polémica en la expresión de la opinión.

\section{Marco teórico: marcadores discursivos y discurso digital en español}

En uno de los primeros estudios sobre la presencia de marcadores en el discurso digital en español, Gómez Torrego (2001) señala que en los correos eletrónicos analizados son frecuentes "conectores anafóricos" como en efecto, claro que sí, bueno, bien, de acuerdo, por fin, que permiten a los hablantes gestionar la interacción y la negociación en ese medio. Por otra parte, en su análisis de las funciones de pues, pero y bueno en los canales de chat, López Quero (2007) subraya el carácter polifuncional de los marcadores. Por ejemplo, el primero suele iniciar la respuesta a una pregunta adquiriendo un valor de intensificador, aunque puede tener también un valor continuativo cuando expresa acuerdo o desacuerdo con el emisor; el conector contraargumentativo pero suele ir precedido de sí, cuando denota expresión sincera, o seguido de $s i$ (pero si) con valor modal de sorpresa o contrariedad; en cuanto a bueno, este presenta, en cambio, un valor metadiscursivo de preconclusión, que permite también atenuar el posible desacuerdo con el interlocutor. En otro trabajo centrado en el empleo de venga en foros de debate y chats, el mismo autor afirma que este marcador conversacional aparece en el discurso digital para marcar la modalidad deóntica volitiva, expresar la metadiscursividad y el enfoque de la alteridad (López Quero, 2010: 192).

En un estudio dedicado, en cambio, el empleo de marcadores en foros de debate especializados, Landone (2009) señala que, en algunos casos, son estructuradores de la información que dotan el discurso de coherencia y cohesión, mientras que en otros son marcadores conversacionales que facilitan el desarrollo de la interacción dialógica. Estos valores permiten a la autora destacar que el discurso en los foros se sitúa entre las variedades concepcionales escrita y oral de la lengua. De hecho, en un análisis sucesivo, en el que se ocupa de cortesía y uso de marcadores en un foro de debate dedicado a la lengua española, muestra que en estos textos se emplean simultáneamente marcadores prototípicos tanto de la va- 
riedad oral coloquial, dialógicos, como de la variedad escrita, monológicos. No obstante, los del primer tipo, como son, por ejemplo, hombre, bueno o mira, presentan una frecuencia y variedad mayores, así como una mayor versatilidad, en la medida en que permiten modular la fuerza ilocutiva en los actos asertivos, estructurar la conversación y negociar el desacuerdo (Landone, 2012: 1816).

Partiendo de una reflexión similar, Sal Paz (2007) observa que, en los comentarios en la prensa digital, los usuarios recurren a menudo a enlaces como entonces o pero con la intención de dar respuesta a comentarios previos y expresar acuerdo o desacuerdo con lo dicho por el interlocutor. En este contexto, no solo tienen funciones de estructuración y cohesión del discurso sino que adquieren también valores modales. Por otra parte, puesto que son textos esencialmente argumentativos, se observa una frecuencia mayor de conectores con valor de oposición (pero), consecutivos (entonces), aditivos (incluso) y explicativos (o sea, es decir) (Pano Alamán, 2015). Este tipo de partículas se combina con marcadores como bueno y hombre, con función interactiva reactiva, muy presentes en las réplicas a otros comentarios en el mismo espacio.

En cuanto a su empleo en las redes sociales, los análisis se han centrado generalmente en Twitter. Loredo y Picone (2012), por ejemplo, investigan en un corpus de tuits el valor de suposición, concesión y sobre todo ironía del marcador ponele, frecuente en el español de Argentina. Por su parte, Pano Alamán y Mancera Rueda (2014) analizan la presencia y funciones de los marcadores interactivos ien serio?, por supuesto, bien, claro, ¿no?, hombre o mira en un corpus de tuits en los que los ciudadanos reaccionan generalmente de forma crítica a lo que tuitean los parlamentarios españoles. Estos elementos aparecen en distintas posiciones en los mensajes para apelar al interlocutor político y expresar acuerdo o desacuerdo con lo que dice. En un estudio similar sobre los marcadores en el discurso político y mediático en el microblog, Padilla Herrada (2016) subraya la relación de los marcadores interactivos que emplean políticos, periodistas y ciudadanos con dispositivos lingüísticos frecuentes en la conversación coloquial prototípica. Marcadores como iverdad?, ¿eh? y ¿no? manifiestan el grado de cooperación o conflicto entre interlocutores, con distintos grados de atenuación o intensificación. Por último, el análisis pragmático-discursivo del marcador ahora con verba dicendi en un corpus general de tuits, llevado a cabo por López Quero (2019), demuestra que este deíctico temporal puede incluirse, junto a ahora bien, entre los marcadores contraargumentativos empleados en Twitter.

Como se apuntaba, en las redes suele instaurarse una dinámica interactiva marcada a menudo por la polémica y la expresión de opiniones sobre cualquier tema. La interacción viene facilitada en gran parte gracias a dispositivos técnicos que fomentan la reacción de los usuarios ante determinados contenidos y que se encuentran en Facebook, Twitter y YouTube, espacios en los que se centra la presente investigación, con formas y funciones similares. Por ejemplo, Facebook se basa en la conexión de perfiles, ya sea entre personas o grupos, en los que cotidianamente aparecen "publicaciones" que el usuario o usuarios comparten con sus contactos. Pueden ser imágenes, vídeos, enlaces, eventos, etc. que quedan reflejados en la línea del tiempo de la biografía o muro del usuario y que otros pueden valorar por medio del dispositivo Me gusta, entre otros, o mediante comentarios, generalmente breves, dirigidos a ese mismo usuario. Estos textos pueden recibir a su vez una respuesta, lo que permite instaurar interacciones de muchos a uno o de muchos a muchos. Twitter es una plataforma de microblogging donde es posible publicar mensajes de no más de 280 caracteres en el propio perfil o cuenta personal o institucional. La interfaz de Twitter, que en los últimos años ha ido cambiando hasta asemejarse a la de Facebook, presenta una columna central denominada cronología, en la que el usuario publica sus tuits, en ocasio- 
nes, creando un "hilo" que reúne en secuencia distintos mensajes sobre un mismo tema, y en la que el usuario puede leer los tuits publicados por aquellos perfiles a los que sigue. Además, gracias a distintos dispositivos visibles debajo de cada mensaje, este puede "responder" a otro tuit abriendo a un intercambio con otros usuarios, compartir (retuit) los mensajes de otros usuarios con sus propios seguidores e indicar que un mensaje le gusta. Por último, YouTube presenta características únicas, pues se trata de una red de compartición de vídeos accesibles desde cualquier dispositivo sin que sea necesario seguir determinados perfiles o entrar en contacto con otros usuarios, en muchos casos, previa petición. Los vídeos pueden ser compartidos, evaluados positiva o negativamente por medio del dispositivo del pulgar hacia arriba o hacia abajo, y comentados -tras acceder a la propia cuenta en YouTube- en un espacio en el que los mensajes de los usuarios registrados se acumulan a veces en pocos minutos. Estos comentarios, que el sistema suele ordenar de más reciente a más antiguo, pueden recibir respuestas, generando en esta plataforma también una suerte de conversación. Este tipo de dinámicas permite afirmar que las redes son espacios en los que predomina la expresión de las opiniones, la argumentación y la persuasión, de ahí el interés por extender el análisis sobre el empleo de los marcadores discursivos a diversas plataformas, desde una perspectiva que tiene en cuenta también su uso en función del grado de coloquialidad o informalidad de los mensajes.

\subsection{Marcadores y variación concepcional lengua hablada y lengua escrita}

Las investigaciones mencionadas previamente se han centrado en las funciones discursivas y pragmáticas de algunos marcadores en específicos entornos digitales. En este trabajo, sin embargo, se intenta ofrecer un estudio sistemático de las funciones de los marcadores presentes en distintas redes sociales, teniendo en cuenta también la variación concepcional escrito/hablado de la lengua. Para ello, se consideran los planteamientos de López Serena y Borreguero Zuloaga (2010) sobre el empleo de marcadores en relación con la variación lengua hablada/lengua escrita. Estas autoras señalan, en primer lugar, que existe una especialización entre los marcadores discursivos por lo que se refiere a su aparición en el discurso oral o escrito, recordando también que son numerosos los autores que han recogido esta idea (2010: 329). Tras revisar los estudios sobre marcadores discursivos en español (Fuentes Rodríguez, 1987, 1993; Pons Bordería, 1998; Portolés Lázaro, 1998, 2010; Montolío Durán, 2001; Loureda Lamas y Acín Villa, 2010; Aschenberg y Loureda Lamas, 2011, entre otros), en los que se señala la relación que se da entre estas partículas y dicha variación, López Serena y Borreguero Zuloaga apuntan que el análisis de sus funciones debería considerar la oposición hablado/escrito como oposición medial -realización fónica frente a la gráfica- y como diferenciación gradual entre las distintas maneras en que se conciben y elaboran los discursos, esto es, en relación con "la concepción subyacente a un enunciado y al modo de su verbalización" (López Serena y Borreguero Zuloaga, 2010: 338, cursiva de las autoras). De ahí que, siguiendo a Koch y Oesterreicher (1990 [2007]: 30), sea preferible establecer una diferenciación no entre lengua hablada y lengua escrita, sino entre inmediatez y distancia comunicativa. 
Basándose en esta diferencia, plantean, en segundo lugar, las macrofunciones interaccional, metadiscursiva y cognitiva ${ }^{1}$. En la primera se incluirían los marcadores prototípicos de la inmediatez comunicativa, que señalan una reacción cooperativa o conflictiva respecto a lo dicho por el interlocutor. Indican los movimientos conversacionales de los interlocutores, por lo que, en su análisis, es necesario considerar quién utiliza el marcador, hablante u oyente. Dentro de esta macrofunción se sitúan las estrategias discursivas que ponen en evidencia la reacción del interlocutor, tanto si esta es colaborativa y corrobora lo que afirma el locutor, como si es reactiva, en la manifestación de desacuerdo o petición de aclaración (López Serena y Borreguero Zuloaga, 2010: 354-357). La función metadiscursiva está relacionada, en cambio, con el proceso de expresión lingüística del discurso, donde es posible identificar los mecanismos cohesivos que lo ordenan y estructuran con el objeto de facilitar su procesamiento, y los que permiten formular lingüísticamente el contenido textual, poniendo de manifiesto la relación entre el hablante y su propio discurso en la fase de planificación y desarrollo. Esta macrofunción puede darse en discursos propios tanto de la inmediatez como de la distancia comunicativa, o concepcionalmente hablados o escritos, aunque algunas subfunciones como la de la estructuración de la información, suelen realizarse "en los textos escritos por un mayor número de elementos de marcación” (López Serena y Borreguero Zuloaga, 2010: 350). La última macrofunción, la cognitiva, se relaciona con los conectores, marcadores que suelen emplearse en discursos concepcionalmente escritos, aunque no de forma exclusiva (López Serena y Borreguero Zuloaga, 2010: 373). Las funciones que se incluyen dentro de esta macrofunción son, entre otras, la de señalar las relaciones lógico-argumentativas que se establecen entre los contenidos proposicionales de los elementos oracionales e interoracionales del texto -función lógico-argumentativa-; entre los contenidos que vehicula el discurso y los conocimientos compartidos o presupuestos por los participantes en la comunicación, y que permiten las inferencias -función inferencial-; o entre el contenido textual y la actitud del hablante -función modalizadora- (López Serena y Borreguero Zuloaga, 2010: 351-352).

\section{Metodología y corpus}

El presente estudio tiene como objetivo principal ampliar los análisis sobre marcadores en las redes sociales teniendo en cuenta su presencia y funciones no solo en Twitter sino también en Facebook y YouTube. Para identificar los más frecuentes en el corpus constituido para los fines de esta investigación, se adopta la clasificación de Martín Zorraquino y Portolés Lázaro (1999) y se consideran algunos planteamientos recogidos en el Diccionario de partículas discursivas del español (Briz Gómez et al., 2008) y en estudios dedicados a los conectores (Domínguez García, 2007) y marcadores interactivos (Cortés Rodríguez y Camacho Adarve, 2005). Asimismo, con el objeto de determinar sus funciones atendiendo a su posición en el continuo entre inmediatez y distancia comunicativa, se aplican al análisis las macrofunciones propuestas por López Serena y Borreguero Zuloaga (2010).

1 Las macrofunciones indicadas pueden desglosarse en varias funciones y subfunciones. Por otra parte, no es posible establecer límites entre las funciones agrupadas en estas tres macrofunciones, puesto que, en un determinado contexto, un marcador puede realizar varias funciones pertenecientes a macrofunciones distintas (polifuncionalidad sintagmática), mientras que otro puede participar en la realización de diversas funciones dependiendo del contexto y del cotexto en que aparezca (polifuncionalidad paradigmática) (López Serena y Borreguero Zuloaga, 2010: 353). 
El corpus está constituido por 3000 mensajes (66915 palabras) publicados en Facebook, Twitter y YouTube², redes informativas en las que se produce un alto grado de interacción entre usuarios que expresan sus opiniones y argumentos en relación con cuestiones de actualidad (Mancera Rueda y Pano Alamán, 2013).

Se compone de mensajes relacionados con la gestión de la reciente crisis del COVID-19 en España, extraídos automáticamente con la herramienta ExportComments. Comprende tres subcorpus constituidos cada uno por: 1000 respuestas a dos tuits publicados el 10 de marzo y el 24 de abril en el perfil del @MinisterioSanidad; 1000 comentarios a dos publicaciones del 19 de mayo y del 1 de junio de la página oficial Ministerio español de Sanidad en Facebook; y 1000 comentarios a dos vídeos publicados en los canales de YouTube de El Mundo (01-03-2020) y El País (14-03-2020), sobre dos conferencias de prensa del Gobierno español en los que se informa sobre la gestión inicial de la pandemia ${ }^{3}$. Incluye, por tanto, las respuestas y comentarios de los usuarios de estas tres redes a contenidos similares provenientes de fuentes institucionales. En este trabajo se han eliminado los datos de los autores por cuestiones de privacidad y se ha optado por reproducir los mensajes como han sido publicados, sin omitir las muestras del subcódigo escrito propio de los textos electrónicos.

\section{Resultados}

Las funciones Wordlist y Ngram del programa Sketch Engine han permitido obtener una lista de frecuencias de los marcadores presentes en el corpus. La Tabla 1 recoge los que presentan un mínimo de diez ocurrencias en el corpus general, distribuidos por red social.

Tabla 1. Marcadores más frecuentes (Total $\geq 10$ )

\begin{tabular}{|l|r|r|r|r|}
\hline MD & Facebook & Twitter & YouTube & TOTAL \\
\hline Conectores & 88 & 67 & 139 & 294 \\
\hline pero & 6 & 5 & 8 & 19 \\
\hline encima & 3 & 10 & 4 & 17 \\
\hline además & 3 & 10 & 2 & 15 \\
\hline incluso & 3 & 1 & 6 & 10 \\
\hline sobre todo & \multicolumn{5}{|l|}{} \\
\hline Estructuradores de la información & 25 & 11 & 32 & 68 \\
\hline pues & \multicolumn{5}{|l|}{} \\
\hline
\end{tabular}

2 Según el Informe Digital 2020, son las plataformas más utilizadas en España, junto a Instagram. Informe disponible en: https://wearesocial.com/es/ blog/2020/02/digital-2020-en-espana

3 Tuits disponibles en: https://twitter.com/SaludPublicaEs/status/1234056474743185408; https://twitter.com/SaludPublicaEs/ status/1253624622215581696; publicaciones en Facebook: https://www.facebook.com/MinSanidad/posts/2535106579922607?comment_ id=2535111529922112; https://www.facebook.com/MinSanidad/posts/2564621386971126?comment_id=2564627350303863; vídeos en YouTube: https://www.youtube.com/watch?v=2LSRyxNQe6U; https://www.youtube.com/watch?v=eakx-GWKoDQ 


\begin{tabular}{|l|r|r|r|r|}
\hline Operadores discursivos & 1 & 4 & \multicolumn{5}{l|}{} \\
\hline por ejemplo & 11 & 2 & 17 & 30 \\
\hline Marcadores conversacionales \\
\hline claro & 7 & - & 6 & 13 \\
\hline hombre & 3 & 1 & 8 & 12 \\
\hline bueno & 3 & 2 & 6 & 11 \\
\hline vamos & 1 & 3 & 7 & 11 \\
\hline ¿eh? & & & 6 & \\
\hline
\end{tabular}

Fuente: elaboración propia

Como es posible observar, los marcadores más frecuentes en las tres redes sociales son los conectores, por un lado, y los marcadores conversacionales, por otro, aunque por orden de frecuencia destacan el conector pero, el estructurador pues y el marcador de modalidad epistémica claro. Se emplean también los conectores aditivos encima, además, incluso y sobre todo, mientras que los conversacionales hombre, bueno, vamos y $i e h$ ?, si bien aparecen en los tres subcorpus, se utilizan sobre todo en comentarios de Facebook y YouTube. Aparece de forma más esporádica aún el operador de concreción por ejemplo. Los reformuladores como en fin (recapitulativo), o sea (explicativo) o la verdad (de refuerzo argumentativo), que suelen emplearse en foros y comentarios en la prensa (Landone, 2012; Pano Alamán, 2015) tienen una presencia anecdótica en estas redes sociales, puesto que no llegan a las diez ocurrencias.

En lo que respecta a la frecuencia (n. de ocurrencias) de uso por tipología y red (Fig. 1), es posible afirmar que el empleo de los conectores y los marcadores conversacionales es preponderante respecto al de los estructuradores, seguidos a distancia por los operadores discursivos. Las cuatro tipologías se emplean en los comentarios en YouTube, mientras que en Twitter se prefiere el uso de conectores respecto a otras tipologías. En el caso de Facebook, los usuarios utilizan frecuentemente también los conectores, mientras que la presencia de marcadores conversacionales y del estructurador pues es menor. 
Fig. 1. Frecuencia de marcadores por tipología y red social

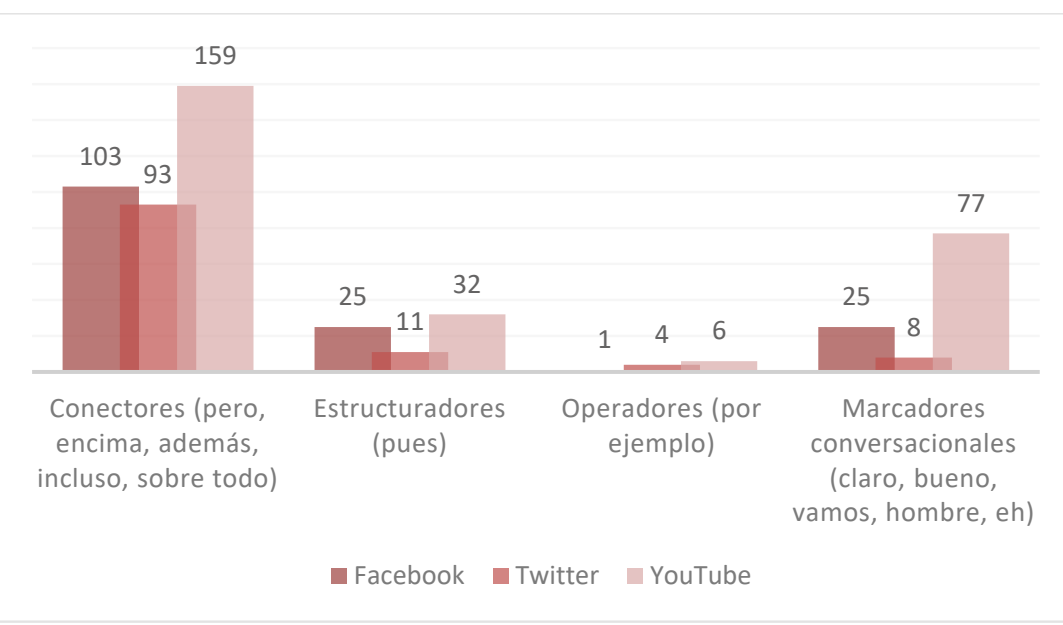

Fuente: elaboración propia

\subsection{Análisis y discusión}

\subsubsection{Pero}

De acuerdo con los datos obtenidos, pero es el marcador más frecuente en las tres redes sociales. Se trata, en todo caso, de un conector muy utilizado en diversos contextos comunicativos, cuyo significado encierra diversos matices (Domínguez García, 2007: 98). En estas plataformas se comporta como conector argumentativo cuando el hablante lo emplea para cancelar las conclusiones del enunciado anterior, por medio del enunciado que introduce:

(1) Mascarillas si, mascarillas no, guantes si guantes no, las gotas por el aire, ahora las superficies no son problemas, sinceramente, no tengo la inteligencia de este señor ,pero es que no quiera tenerla porque es un donde dije digo, digo Diego Nos pueden decir un trocito de verdad????? Si no lo hacen por ellos ,que lo hagan por los sanitarios [...] (Facebook, 19-05-2020).

(2) Señor Presidente, entiendo que es complicado organizarse en medio de una pandemia, pero en serio no hay otra forma? Los menores de 6 a 12 años, donde se quedan si sus padres como yo por ejemplo tengo que ir a trabajar para que otras familias vayan a trabajar? (Twitter, 28-04-2020).

(3) Efectivamente. En España se debió actuar de forma enérgica tras el primer caso, allá por el 31 de Enero, nadie habría entendido las medidas, pero un buen epidemiólogo habría sabido que cuando el primer caso ya había otros 50 o 100 y lo habría explicado bien al país y a sus dirigentes. [...] (YouTube, 01-03-2020).

Como vemos, uno de sus valores argumentativos más frecuentes es el restrictivo. En estos casos admite el primer enunciado de su relación, por ello el hablante, recurre, por ejemplo, a la primera persona del singular ("entiendo", "no tengo") o 
a "efectivamente", que confirma una opinión anterior, para cancelar después las posibles inferencias que se derivan de ese enunciado (Domínguez García, 2007: 99). En los ejemplos tiene, pues, una función lógico-argumentativa antiorientada que se manifiesta en mensajes más propios de la variedad concepcional escrita del discurso (López Serena y Borreguero Zuloaga, 2010: 360 y 378). No en vano, aparece en enunciados sintácticamente más elaborados que se dirigen al auditorio o al conjunto de seguidores y no a un interlocutor específico, y que se colocan detrás de una coma o de un inciso.

Dentro de esta función argumentativa antiorientada, adquiere también valor de oposición débil cuando, aun expresando una oposición contraargumentativa, el hablante introduce una explicación. El enunciado que introduce pero cancela una conclusión del enunciado previo a la vez que justifica esa cancelación (Domínguez García, 2007: 103):

(4) Y viajar a partir de cuando? En mi caso, yo soy española y estoy confinada aquí, pero por trabajo pasó largas temporadas en otro país y necesitaría saber cuando aproximadamente se abrirá el espacio aéreo. Gracias (Twitter, 29-04-2020).

(5) estoy de acuerdo, aunque tampoco hay que olvidar que la salud no es una variable independiente. Si le economía se va a la mierda y hay una recesión (que la va a haber), eso también termina teniendo consecuencias a medio largo plazo sobre la salud de las personas. No es todo tan sencillo. La gente está contraponiendo salud a economía como si fueran cosas independientes, pero no lo son, hay que tener cuidado (YouTube, 14-03-2020)

En estos mensajes, pero señala que el segundo segmento es el de mayor peso informativo y el que determina la orientación argumentativa del enunciado (Fuentes Rodríguez, 1998: 37). Asimismo, presenta en estos casos un "valor metadiscursivo de control del acto de decir" (Domínguez García, 2007: 106). Aparece sobre todo en comentarios monológicos que ponen en tela de juicio lo que se dice en el tuit o la publicación en Facebook del ministerio o en el vídeo de la conferencia de prensa institucional en YouTube.

Sin embargo, notamos que también se emplea a menudo en réplicas dirigidas a otros usuarios en la misma red social, de tal manera que al valor restrictivo del conector se une un valor refutativo, normalmente asociado a contextos dialógicos (Domínguez García, 2007: 101). La oposición se establece entre lo que dicen distintos enunciadores (Portolés Lázaro, 1995: 259-263), de forma que es posible incluirlo entre los marcadores con función interactiva reactiva, con los que el hablante se opone a la intervención previa, a veces para poner en duda la exactitud de lo aseverado por el interlocutor (López Serena y Borreguero Zuloaga, 2010: 361), como en (6), cuestiona al tuit del ministerio, o para atenuar una crítica a lo que dice otro participante:

(6) Pero vamos a ver... Si a las $15 \mathrm{hrs}$ desde Sanitat dicen que hay 63 casos, ¿ cómo narices a las $18 \mathrm{~h} r$ hay 50 casos en la Comunidad Valenciana? ¿Qué números estáis haciendo? ¿Nos tomáis a todos por tontos o qué? Ya ni números sabemos hacer, con lo fácil que es sumar... (Twiter, 10-03-2020).

(7) A: QUÉ gracioso, pues yo DISCREPO, tengo un familiar con úlceras de decúbito, con 94 años, y su enfermera no viene a curar la, porque dice que por protocolo no urgente. QUÉ pasa que como hay PANDEMIA dejan a PERSONAS incapacitadas para que se mueran!!!!!. [...]

B: Los sanitarios siguen ordenes sienpre no cargues sobre ellos la culoa que tienes los que dirigen amigo. Los medicos y sanitarios serian los primeros en querer atender a todo el mundo y ayudarlo. Pero aunque sea cruel el problema de tu 
familia afecta solo a tu familiar, mientras que esto nos afecta a todos y al. Propagarse suben las muertes. Se que no es justo soll es l explicacion. Pero repito las ordenes no las dan ellos (YouTube, 14-03-2020).

En estos comentarios, marca la oposición entre dos segmentos que llevan a conclusiones opuestas, pero entre los que hay alguna relación. Algunos de los comentarios en los que se utiliza, pero se combina con otras partículas. Se trata de estructuras como pero bueno, que suele atenuar lo que se va a decir al contraargumentar (8), y pero claro en (9), que deja de lado lo dicho, aun aceptándolo en cierto modo, para pasar a otra cuestión que el hablante considera de mayor peso argumentativo y para afirmar su posición. En este caso tiene por tanto un valor metadiscursivo, como marca de transición a otro aspecto discursivo (Domínguez García, 2007: 107):

(8) A: ¿te hace falta que te lo digan? ¿crees que a la gente que se hizo su propia mascarilla se lo dijo el gobierno? B: pues si. De hecho yo trabajo en un centro medico y los medicos nos decían que las quirúrgicas no hacian nada para evitar el contagio, ya que las partículas atravesaban el tejido. Ahora cualquier trozo de tela vale...Así que algo no cuadra de la información. Pero bueno supongo que a todos nos deja más tranquilos ver al de al lado con la boca tapada aunque sea con un trozo de tela de florecitas (Facebook, 19-05-2020).

(9) Que vergüenza dais. Si hubierais hecho algo antes esto no hubiera pasado. Pero claro era más importante las manifestaciones que la salud. Venga hombre venga. De que coño vais... (YouTube, 14-03-2020).

\subsubsection{Encima, además, incluso y sobre todo}

En el grupo de los conectores identificados en el corpus, destacan también los aditivos encima, además, incluso y sobre todo. Respecto a los dos primeros, cabe recordar que mediante encima "se concede una valoración personal al segundo argumento: se añade un valor modalizante del que carece además" (Domínguez García, 2007: 66). En estos comentarios, encima y además ordenan los segmentos del discurso en una escala aditiva, de tal manera que el segmento que introducen es más fuerte argumentativamente. Los mensajes en los que aparecen están dirigidos al auditorio y, por su extensión, el empleo de incisos y uso de otros marcadores en estructuras oracionales coordinadas y subordinadas, se acercan a la variedad concepcional de la lengua escrita en mensajes de las tres redes como los siguientes:

(11) No engañéis. Las quirúrgicas costaban 0,40 ahora 0,98...precio "oferta del Gobierno", hay que usar una por lo menos al día y te puedes contagiar, no se sabe quien es asintomático. La FFP2 cuestan 6 pero duran 1 mes y además previenen de contagiarse a quien la lleva. SOMOS TONTOS ??? (Facebook, 19-05-2020).

(12) No tenéis ni idea de lo que habéis aprobado, y encima basándoos en bulos y mentiras contrastadas como tal. Que poca vergüenza tenéis (Twitter, 28-04-2020).

(13) Y pensar que hay gente que aún defiende este sistema putrefacto. Que poco espíritu crítico que hay .... Y como encima nuestros políticos no deciden de nada, pues todo lo deciden en Alemania........] La verdad es que el euro ha sido la ruina de España, pero pocas voces lo explican !!! (YouTube, 01-03-2020).

En el caso de incluso, se trata de un marcador que vincula semántica y pragmáticamente dos segmentos de discurso, por ello tiene una función metadiscursiva estructuradora de la información con función focalizadora. En este sentido, añade un último argumento como si fuera el más relevante (López Serena y Borreguero Zuloaga, 2010: 365-366). De hecho, este 
es un adverbio de foco (Portolés, 2010: 295), cuya función es focalizar determinados constituyentes del enunciado. Como se observa en (14), el foco se sitúa en el segundo miembro, en el que el hablante destaca que se confiscaran las mascarillas que provenían del extranjero:

(14) Antes no, ahora sí. Después que acabaron con las mascarillas e incluso confiscaron las que venía desde afuera (yo fui un afectado por esto) ahora las "exigen" por tener controlado el negocio de las mascarillas? Como juegan con la salud de la gente, irresponsables! (Facebook, 19-05-2020).

Asimismo, desempeña en estos mensajes una macrofunción cognitiva al relacionar dos argumentos coorientados en una escala creciente en lo que concierne a su fuerza argumentativa (García Negroni, 2000). En los casos que siguen es realizante (Portolés Lázaro, 1998: 95), puesto que, además de mantener la misma orientación discursiva, incrementa la fuerza del argumento que introduce:

(15) En la empresa privada estarías en la puta calle isofacto. Pero como es el gobierno que paga todo el mundo (Incluso los que no los votamos) NO PASA NADA!!! Ahí no dimite nadie! (YouTube, 01-03-2020).

(16) A: mucho imbecil sin clases va a tirar pa las fallas y se va a aumentar muuucho mas, o las cancelais o de nada sirve la contención minima

B: y cancelar clases en catalunya pa cuando?

C: En Asturias incluso hay colegios sin niños durante todo el año (Twitter, 10-03-2020).

Se ha hablado, de hecho, del sentido enfático de incluso, que "se puede relacionar con el matiz relativo a la falta de expectativas [...] en la medida en que la oración en que se haya incluso es, en principio, una oración que no se espera que se produzca (porque expresa algo que no se espera que suceda), y aquello que no se espera tiene más valor, cuando se produce, que aquello que se prevé" (Cuartero Sánchez, 2002: 144).

Aunque su frecuencia es menor, en particular en Twitter, cabe mencionar dentro del grupo de los conectores la partícula sobre todo, con función argumentativa de coorientación aditiva, que introduce "un argumento siempre de mayor importancia, y sin establecer grados escalares” (Domínguez García, 2007: 72), por lo que no puede equipararse a los marcadores previos:

(17) a ver, se hace obligatorio llevar mascarilla, pq vamos pasando de fases y entonces, hay más gentes juntas y lo mejor para prevenir, es la mascarilla, sin ella, estaríamos todo el tiempo, viendo las distancias, q a veces, se nos puede pasar, sobre todo en las tiendas. (Facebook, 19-05-2020).

En estos casos, es posible destacar los matices presuposicionales que se derivan de las partículas empleadas por los usuarios y que permiten inferir la existencia de otras alternativas a las que se proponen en el constituyente focalizado o situarlo en una hipotética escala de probabilidad. Por ejemplo, incluso, además de destacar el foco, lo pone en relación con otras alternativas que pueden aparecer explícitas o implícitas, es decir, que se presuponen en ese contexto (Portolés, 2010: 297). Estas funciones son particularmente evidentes en las redes sociales, las cuales suelen regirse por un principio de economía lingüística (Mancera Rueda y Pano Alamán, 2013: 41). 


\subsubsection{Pues}

El comentador pues es el segundo marcador más utilizado en el corpus general. En estos mensajes tiene generalmente un doble valor argumentativo e ilocutorio (Briz Gómez, 1993: 173), que se manifiesta en las intervenciones reactivas, por lo que es posible situarlo entre los marcadores con macrofunción interaccional, cuyas funciones son "señalar los movimientos conversacionales de los interlocutores" y "manifestar una cierta actitud ante la información recibida” (Borreguero Zuloaga y López Serena, 2010: 178). En los mensajes analizados expresa desacuerdo total (18) o parcial (19) respecto a lo dicho por el interlocutor previamente. En el primer caso, el hablante se opone abiertamente al contenido del tuit del ministerio negando su veracidad; en el segundo, B limita o reduce la relevancia de lo dicho por su interlocutor respecto a la capacidad del Gobierno para buscar soluciones (véase también el empleo de "yo creo" como estrategia atenuadora del desacuerdo):

(18) Tan pocos, enserio, pues yo no les creo nada, sean honestos (Twiter, 10-03-2020).

(19) A: nos están entreteniendo con mascarillas si mascarillas no y mientras la gente no para de hablar del tema todo lo demás se olvida, al pueblo pan y circo.

B: pues yo creo que el gobierno está entretenido en buscar soluciones para todos, en tres meses se han tomado más medidas y buscado más soluciones que en muchas legislaturas completas. [...] Los entretenimientos los buscan otros, no los crea el gobierno (Facebook, 19-05-2020).

También vehicula una respuesta colaborativa cuando el hablante manifiesta su acuerdo con la opinión de otro usuario, como en (20). Sin embargo, este valor se manifiesta en pocos mensajes reactivos en Facebook y YouTube, de manera que su función en este contexto es prevalentemente la de vehicular el desacuerdo:

(20) A: Un respeto a este hombre que es todo un experto, por eso lo han cogido (y ya te digo que no tiene ni el menor interés por la política). [...]

B: pues será eso... yo no lo digo movido por ningún motivo político (YouTube, 01-03-2020).

Como vemos, al situarse al inicio de los comentarios reactivos, se comporta como conector y como comentador prototípico de la variedad oral coloquial de la lengua, además de introducir un comentario nuevo (Portolés Lázaro, 1998; Porroche Ballesteros, 1996).

Por otro lado, dentro de la macrofunción cognitiva que señala las relaciones lógico-argumentativas que se establecen entre los contenidos proposicionales del texto y, en los siguientes mensajes, entre el contenido textual y la actitud del hablante (López Serena y Borreguero Zuloaga, 2010: 375-376), el marcador presenta funciones metadiscursivas y argumentativas coorientada causal (21) y consecutiva (22), valores que se excluyen en el Diccionario de partículas discursivas (Briz Gómez et al., 2008). En esta ocasión son más próximas a la variedad concepcional escrita. Como puede notarse, se trata de mensajes con una mayor extensión, en los que se emplean también otros marcadores y estructuras oracionales hipotácticas: 
(21) He tenido mucha paciencia con este gobierno pues sé que no es fácil el papel que os ha tocado,con Casado que no deja ni trabajar, pero no nos falléis os votamos no queremos derechas pero necesitamos una izquierda sincera, [...] (Twiter, 04-062020).

(22) Y yo a todo el mundo le escuchaba decir que esto era como una gripe... Que una gripe mataba a 6 mil personas al año... Yo no necesito que me digan las cosas... Veo y actuo... Pero hay borregos que se creen todo lo que les dicen... Y como dijeron que aqui no llegaba y que era como una gripe pues viva la vida... [...] (Facebook, 19-05-2020).

\subsubsection{Claro}

Otro marcador frecuente en el corpus es claro, marcador conversacional de modalidad epistémica que, sobre todo en Facebook y YouTube, expresa evidencia y se interpreta como reforzador de la aserción, véase cómo en (24), el autor del mensaje adopta las mayúsculas para intensificar el enunciado e imponer su opinión a los otros participantes:

(23) Lo están acelerando todo muy rápido y claro ahora no hay ningún muerto,mienten más que hablan y al final lo pagaremos todos con nuevos rebrotes ,ole y ole la gestión que hacen [...] (Facebook, 01-06-2020).

(24) SEÑOR SIMÓN QUE DIJO???..NO PASA NADA..JAJA, YA LLEVAMOS 2097 CASOS. Y SUBIENDO..Y OSÁIS COMPARARNOS CON CHINA Y COREA?..ACASO FUMIGÁIS LAS CALLES Y CIUDADES COMO CHINA Y COREA?...[...] ..NOOO SÓLO OS PREOCUPA LA SEMANA SANTA DE SEVILLA, EL 8 DE MARZO, EL FUTBOL, ETC EN VEZ DE APLAZARLO, CLARO COMO LOS FUNCIONARIOS COBRARÉIS EL 100\% DEL SALARIO POR BAJA Y LOS CURRITOS EL 70...[...] (YouTube, 01-03-2020).

En estos mensajes permite al hablante evaluar la evidencia del miembro del discurso que introduce en relación con datos que se hallan en el discurso, en el contexto, o que se presuponen en la mente del hablante o en la de los participantes en esa interacción (Martín Zorraquino y Portolés Lázaro, 1999: 4150). En (24), por ejemplo, claro introduce un enunciado que alude al cobro del $100 \%$ del salario por parte de los funcionarios, a los que se dirige mediante la segunda persona de plural, para apoyar su argumento, esto es, que a los funcionarios del Ministerio de Sanidad no les preocupa la situación de pandemia.

Por otra parte, en la interacción puede desencadenar procedimientos de cooperación entre los interlocutores, al señalar un posible acuerdo entre estos. Nótese cómo en este intercambio, B emplea claro para confirmar lo dicho por A y, al mismo tiempo, redundar en el argumento que este último ha introducido en su mensaje, el de la insinceridad y poca credibilidad del Gobierno:

(25) A: Como si fuéramos niños, desde un principio aver sido sincero que es y fue obligatorio pero que no habían y ya está. Hay que ser consecuente, de esta manera no hacéis más que quitaros credibilidad

B: Claro no decía la verdad porque sabía que no habían en el mercado, nos han nentido. Nos manejan según conviene.

[...] (Facebook, 19-05-2020).

Sin embargo, cuando se sitúa en posición inicial en este tipo de comentarios, es más habitual que vehicule el desacuerdo, cuando admite una concesión que introduce sucesivamente una restricción (Landone, 2012: 1812). En otros casos, como se observa en (27), expresa incluso una actitud crítica con intención irónica, por la que el hablante invita al oyente a inferir lo contrario respecto a lo que afirma explícitamente: 
(26) Claro, ni se molestan en actualizarlas. Sólo le han cambiado la hora. Se están riendo de la gente (Twitter, 28-04-2020).

(27) A: Y? Que se pretende demostrar con este video? Que la situacion ha ido cambiando? Que se han ido adaptando las medidas segun el escenario?

B: Claro, la situación cambia porque si, no por incompetencia (YouTube, 01-03-2020).

También puede aparecer como enunciado independiente en mensajes breves que se situán en el polo concepcional oral de la lengua, aunque este empleo es más limitado en el corpus, en la fórmula claro que sí, que en el siguiente mensaje intensifica también la ironía:

(28) De ministro un filósofo! Claro que si (Facebook, 19-05-2020).

\subsubsection{Bueno, vamos yeh}

Otros marcadores conversacionales empleados en las tres redes sociales son hombre (que no aparece en Twiter), bueno, vamos y eh (con una sola ocurrencia en Facebook). En los mensajes analizados, hombre se comporta como unidad interjectiva en comentarios interactivos reactivos, donde se emplea con la voluntad de atenuar la "expresión de la disconformidad con lo dicho por el oyente [...]” (Martín Zorraquino y Portolés Lázaro, 1999: 4173-4174) y salvaguardar la imagen positiva del hablante. En estos mensajes suele aparecer al inicio del enunciado, aunque se sitúa a veces en el cierre, normalmente en comentarios que pueden situarse en la variedad concepcional oral de la lengua, como muestra en estos dos casos el uso alejado de la norma en la puntuación o el empleo de dispositivos prototípicos del español coloquial en estos contextos como el alargamiento de vocales o la reproducción gráfica de la risa:

(29) A: [...] Lo del tabaco por desgracia hay mucho fumador en este país. El síndrome de abstinencia es muy malo. (No fumo), pero entiendo al que sí.

B: si hombre lo que les importará a ellos que tú pases el mono si no puedes fumar hahahaha [...] (YouTube, 14-03-2020).

(30) Porque hace dos meses decía q las mascarillas no valen pa na?aver si te aclaras hombreeeee (Facebook, 19-05-2020).

El marcador bueno, que sí aparece en las tres plataformas, aunque con una sola ocurrencia en Twitter, suele emplearse, de acuerdo con las principales clasificaciones, en enunciados tanto dialógicos como monológicos (Fuentes Rodríguez, 1993: 217-218). Este rasgo se observa también en las plataformas consideradas donde desempeña distintas funciones. Por ejemplo, puede comportarse como formulador lingüístico de ilación discursiva. En este sentido, presenta el miembro del discurso en el que aparece como una continuación de lo dicho previamente. Sin embargo, como se observa en estos ejemplos, el enunciado introducido por bueno sustituye o matiza algún elemento del discurso anterior, aportando nueva información que el hablante considera más relevante o apropiada:

(31) No es necesario las mascarillas No no si es necesario en lugares cerrados Bueno ahora en lugares abiertos también Bueno si vas al campo no hace falta Bueno tú pontela desde que salgas de casa si eso...Tampoco es muy importante solo habrá algún caso aislado en España de Coronavirus [...] (Facebook, 19-05-2020).

(32) Están esperando que se mueran más pensionistas,por eso no hacen nada, bueno si hacen, Mienten como perras (YouTube, 01-03-2020). 
En el corpus, desempeña también una función metadiscursiva cuando, por ejemplo, orienta el fin del enunciado, o indica preconclusión del mismo, como en el siguiente mensaje en el que también se manifiestan elementos propios de la lengua oral que se reproducen en la escritura digital:

(33) Que cierto !!!Algo que no han dicho de un principio. Sabiendo que tenía que ser obligatorio. Pero como no hicieron previsión de material MÍNIMO. Ellos mismos fueron los que dejaron a España sin mascarillas, para poder abastecer los Hospitales. NUESTROS HÉROES !!!! Que estaban vendidos !!!Quedándose con todos los canales de distribución de las Farmacias. AHORA Bueno Mejor tarde que nunca !!! (Facebook, 19-05-2020).

Asimismo, atenúa el desacuerdo en comentarios reactivos (Portolés Lázaro, 1998: 108). Como se puede notar en (34), C se dirige a $B$ en ese intercambio entre tres participantes en el debate para poner en duda sus palabras, a través de la crítica implícita y mitigada, mediante la partícula inicial, al presidente de Estados Unidos y a su capacidad para afrontar la crisis, en comparación con lo que está haciendo el Gobierno español:

(34) A: Con todo mi respeto.. Me parece que al decir que las peluquerías pueden abrir..se está riendo de todos los sanitarios y demás personas que estamos encerradas en casa queriendo que esto termine.. [...] Esto qué es ... Es irrisorio..de vergüenza B: De verdad.....que ridículo... jamás dirían eso en EEUU.....

C: Bueno vuestro presidente tampoco es ningun lumbreras eh? (YouTube, 14-03-2020).

Dentro del grupo de los marcadores interactivos se sitúa vamos, cuya función suele ser la de llamar la atención del interlocutor (Cortés Rodríguez y Camacho Adarve, 2005: 17). En los mensajes analizados se coloca en posición inicial del enunciado, normalmente en intervenciones dirigidas al conjunto de participantes en la interacción. El análisis muestra que en estos mensajes presenta el miembro del discurso en el que aparece como una matización o precisión de lo que se acaba de decir, como en este comentario:

(35) Cuando la cosa estaba peor...eran desaconsejables y ahora que se ve un pelín de luz...son muy aconsejables. Vamos,... obligatorias. Lo que hace tener abastecimiento!!!! (Facebook, 19-05-2020).

Otras veces, se utiliza vamos para introducir un resumen o una conclusión de lo dicho generalmente en el tuit, publicación o vídeo institucional, como premisa al comentario propiamente dicho:

(36) Vamos que el coronavirus ha venido para quedarse y ahora tendremos que aguantar la gripe y el covid-19 a la vez cada invierno si la gripe ya molesta encima esto, pues anda que si alguien pilla los dos al mismo tiempo va listo por que los virus no esperan por turnos. (YouTube, 01-03-2020).

(37) Vamos que como estábamos desde ayer, no ha cambiado nada, entonces para que esta rueda de prensa? (YouTube, 14-032020).

En el siguiente intercambio en Facebook, adquiere una función atenuadora que permite al hablante evitar responsabilidades sobre lo dicho y un posible desacuerdo. Nótese en este ejemplo, en el comentario de C, la combinación de la partícula con digo con función anafórica, que atenúa lo asertado, junto a los puntos suspensivos, y con macho, que en este caso podría considerarse una variante de hombre enfocador de la alteridad:

(38) A: Pero cuantas veces vas ha cambiar de opinión, no te da vergüenza, DIMISIÓN 
B: propón soluciones tu en vez de criticar!

C: por mucho que Teresa proponga , a quien le pagas para que haga su trabajo es el que lo tiene que hacer!!! Vamos digo... macho dejar a las personas que opinen (Facebook, 19-05-2020).

Por último, aparece en un par de ocasiones como enunciado independiente en mensajes de respuesta breves, adquiriendo un valor de incitación:

(39) A: Hermanos españoles, quédense en casa y tomen todas las precauciones. Soy de Italia, Emilia Romagna, tenemos buenos hospitales, pero este virus parece un tsunami, [...].

B: Vamos fuerza!!!! (YouTube, 14-03-2020).

A pesar de su escasa presencia en el corpus general, cabe mencionar también el marcador conversacional metadiscursivo ¿eh?, cuya función en los mensajes analizados parece ser la de señal apelativa. Por ejemplo, en los mensajes que siguen, apela al oyente solicitando de forma reforzada (Briz Gómez et al., 2008) que confirme o acepte lo dicho por el hablante (40), o bien lo que se le pide (41):

(40) hombre sin exagerar ... que la campaña: la mascarilla no es necesaria durante casi tres meses no se la inventó la gente ... y ahora que ya se lo han creido ... cambiamos !! Ni los buenos son tan buenos ... ni los malos tan malos eh ? (Facebook, 19-052020).

(41) En serio, deje de copiar y pegar, es tremendamente aburrido,... continúe en otra página.... si quiere ¿eh?... En fin... (YouTube, 01-03-2020).

Además, en (40), el hablante busca la petición de conformidad por parte del destinatario ante la aseveración aventurada con anterioridad ("ni los buenos son tan buenos ... ni los malos tan malos"). En definitiva, se pretende someter esa propuesta a la consideración de quienes están comentando en ese espacio.

\subsubsection{Por ejemplo}

Por último, se señala el empleo mucho más limitado aún del operador discursivo por ejemplo, que cuenta con un mínimo de 10 ocurrencias en el corpus general, de las que 6 aparecen en comentarios de YouTube. Se trata de una partícula que presenta el miembro del discurso que lo incluye como caso o ejemplo concreto, en enunciados concepcionalmente distantes o más propios de la variedad concepcional escrita. Como se observa en el siguiente comentario de mayor extensión, dirigido a un interlocutor genérico, esto es, a la audiencia imaginada en ese canal de vídeos, el marcador se incluye en una posición intermedia para apoyar, mediante un ejemplo ilustrativo, el argumento relativo a la dificultad de mantener 1 metro de distancia entre las personas en los espacios cotidianos:

(42) se supone que se prohíbe todas las actividades de puntos de reunión, [...] supongo que a partir de ahora se pondrá límites en distancia con los humanos de 1 metro,,, por ejemplo en un ascensor en vez de entrar 4 personas entrarán solo 2 mantenimiento ese metro de distancia, lo mismo en el metro y autobús y avión mínimo un metro de distancia y en los taxis en vez de 3 o 4 personas dentro solo 1 detrás del vehículo, el vehículo si hay 2 es ya fuente de propagación también o se hace bien o se hace bien mal (YouTube, 14-03-2020). 


\section{Conclusiones}

El análisis llevado a cabo muestra que en las redes sociales Facebook, Twitter y YouTube predominan los conectores y los marcadores conversacionales o interactivos, que se emplean generalmente para modular la fuerza ilocutiva del propio enunciado y manifestar acuerdo o desacuerdo respecto a lo que se dice en otros mensajes. Se trata de marcadores prototípicos de la inmediatez comunicativa que desempeñan funciones propias de las macrofunciones interactiva, como señalar la reacción -manifestación de acuerdo o desacuerdo- ante lo que afirma el interlocutor (López Serena y Borreguero Zuloaga, 2010: 354-357), y cognitiva, como expresar las relaciones argumentativas entre enunciados. En los mensajes analizados, pues presenta un doble valor argumentativo e ilocutorio (Briz Gómez, 1993: 173), que se manifiesta en intervenciones reactivas para indicar desacuerdo con lo que se ha dicho previamente. Pero, conector lógico-argumentativo con mayor frecuencia en el corpus por las distintas funciones que puede desempeñar y los valores que adquiere en el discurso, se relaciona principalmente con las macrofunciones cognitiva y metadiscursiva. La primera incluye la función lógico-argumentativa que pero desempeña de forma similar en las tres plataformas, con el objeto de cancelar -función lógico-argumentativa antiorientada- las conclusiones del enunciado anterior a través del enunciado que introduce y que contiene a menudo una explicación. Dentro de esta función adquiere un valor restrictivo, en mensajes que pueden situarse en la variedad concepcional escrita del discurso (López Serena y Borreguero Zuloaga, 2010: 360). Se trata de enunciados sintácticamente más elaborados que se dirigen al conjunto de usuarios, a la audiencia imaginada en las redes, y no a un interlocutor específico en forma de réplica. En este sentido desempeña también una macrofunción metadiscursiva, relacionada con el proceso de expresión lingüística del discurso, como mecanismo de cohesión, y donde vehicula valores metadiscursivos de control del acto de decir (Domínguez García, 2007). Otros conectores muy empleados en las tres redes con estas dos macrofunciones son pues, cuando vincula argumentos coorientados con valor consecutivo en mensajes más propios de la variedad concepcional escrita; e incluso, además y encima, que expresan argumentos coorientados de adición en escalas crecientes o que focalizan e incluso intensifican el valor ilocutivo de determinados constituyentes del enunciado.

El análisis ha mostrado que pero suele aparecer también de forma frecuente en réplicas dirigidas a otros usuarios, generalmente en Facebook y YouTube, de forma que al valor restrictivo del conector se une un valor refutativo, que suele manifestarse en contextos dialógicos y en mensajes que se sitúan en el polo de la inmediatez comunicativa o concepcionalmente hablados. Dicha oposición se establece entre lo que dicen distintos enunciadores, por lo que se puede incluir entre los marcadores con macrofunción interactiva reactiva, mediante los cuales el locutor se opone a la intervención previa para poner en duda la exactitud de lo aseverado por su interlocutor (López Serena y Borreguero Zuloaga, 2010: 361) o para atenuar una crítica a lo que dice otro participante. Este dato no sorprende si se considera que estos son textos argumentativos breves publicados en espacios que promueven la interacción polilógica de carácter polémico, en particular, en YouTube (Bou-Franch y Garcés-Conejos Blitvich, 2014).

Otros marcadores con macrofunción interactiva frecuentes son claro, que se utiliza sobre todo en Facebook y YouTube y en mensajes más cercanos a la variedad oral coloquial, o concepcionalmente hablados, para expresar evidencia y reforzar la aserción, a menudo en combinación con pero. Son menos frecuentes, en cambio, hombre, bueno, vamos y ieh?, con 
función modalizadora, y que se emplean como atenuadores de la fuerza ilocutiva de algunas aserciones normalmente en respuestas a algunos tuits y en comentarios de réplica a otros comentarios en las otras dos plataformas. En general, estos asumen más de una función de naturaleza pragmática, de modo que adquieren distintos sentidos en función del contexto en el que aparecen, asociándose en ocasiones con otras partículas (pero bueno). En relación con este aspecto, cabe señalar que este tipo de partículas invitan muy a menudo a presuponer los contenidos implícitos que vehicula el mensaje, al emplearse en mensajes breves que expresan una reacción a contenidos publicados en un determinado perfil o canal o a otros mensajes, de forma inmediata y desde dispositivos móviles, y en los que predomina la economía lingüística.

Los textos analizados, en particular, los tuits, presentan un cuadro bastante limitado en lo que respecta a la presencia y funciones de estas partículas en las redes. Se observa una tendencia a privilegiar un grupo restringido de partículas (pero, pues, claro), que desempeñan las macrofunciones interactiva, cognitiva y discursiva, en función del tipo de mensaje -reacción a un determinado contenido o réplica al mensaje de otro usuario- y la intención comunicativa de quien habla. Estas permiten expresar una crítica hacia el locutor institucional, señalar acuerdo o desacuerdo con ese interlocutor o con otro participante en el mismo espacio de debate, precisar o matizar lo dicho e intensificar o atenuar lo asertado por el propio hablante o por su interlocutor. Esos tres marcadores adquieren, pues, valores distintos de acuerdo con el tipo de "respuesta" (Twitter) o "comentario" (Facebook y YouTube) más o menos cooperativo o reactivo en el que aparecen. En este sentido, el estudio corrobora en parte los resultados de investigaciones previas sobre el empleo de los marcadores en chats, foros de debate y comentarios en la prensa digital (López Quero, 2007; Landone, 2012; Pano Alamán, 2015).

Por otro lado, los conectores y marcadores conversacionales identificados suelen aparecer en comentarios de Facebook y, sobre todo, YouTube. En Twitter, en cambio, es preponderante el empleo de conectores. Este dato parece indicar una diferencia entre esta y las otras redes sociales en lo que respecta al uso de marcadores, debido quizá a la diversa concepción y elaboración del mensaje, cuya extensión no debe superar los 280 caracteres, y al tipo de interacción dentro de "hilos", en los que puede ser más complejo visualizar el mensaje que inicia el hilo y distinguir las respuestas al mismo. Las interfaces de YouTube y Facebook permiten activar la visualización de los comentarios, donde es posible identificar inmediatamente el mensaje inicial y la o las respuestas que recibe. En este sentido, el usuario percibe quizá de forma más evidente que participa en un espacio en el que predomina el intercambio entre distintos usuarios. Esta hipótesis y otros aspectos explorados en este trabajo invitan a seguir reflexionando sobre la influencia de los factores tecnológicos y sociosituacionales de la interacción en las redes sociales en el empleo o desempleo de determinados marcadores, concepcionalmente orales o escritos, del español. Para ello es necesario ampliar los corpus de estudio e indagar cada una de las funciones que desempeñan estas partículas en entornos digitales en los que predomina la expresión de la opinión.

\section{Referencias bibliográficas}

Aschenberg, H.; Loureda Lamas, Ó. (2011). Marcadores del discurso: de la descripción a la definición. Madrid/Frankfurt: Iberoamericana/Vervuert. DOI https://doi.org/10.31819/9783865278760

Bou-Franch, P.; Garcés-Conejos Blitvich, P. (2014). Conflict management in massive polylogues: A case study from YouTube. Journal of Pragmatics, 73, 19-36. DOI https://doi.org/10.1016/j.pragma.2014.05.001 
Briz Gómez, A. (1993). Los conectores pragmáticos en español coloquial (I): su papel argumentativo. Contextos, XI/21-22, 145-188.

Briz Gómez, A. (2014). Hablar electrónicamente por escrito. CHIMERA: Romance Corpora and Linguistic Studies, 1, 77-89. Disponible en: https://revistas.uam.es/index.php/chimera/article/view/255/243 [Consultado el 12-05-2020].

Briz Gómez, A.; Pons Bordería, S.; Portolés Lázaro, J. (coords.) (2008). Diccionario de partículas discursivas del español. Disponible en: http://www.dpde.es [Consultado el 17-05-2020].

Cantamutto, L.; Vela Delfa, C. (2020). Mensajes, publicaciones, comentarios y otros textos breves de la comunicación digital. Tonos digital, 38, 1-27. Disponible en: https://digitum.um.es/digitum/bitstream/10201/86441/1/2394-6691-1-PB. pdf [Consultado el 22-05-2020].

Cortés Rodríguez, L.; Camacho Adarve, $\mathrm{M}^{\mathrm{a}} \mathrm{M}$. (2005). Unidades de segmentación y marcadores del discurso: elementos esenciales en el procesamiento discursivo oral. Madrid: Arco/Libros.

Cuartero Sánchez, J. M. (2002). Conectores y conexión aditiva. Madrid: Gredos.

Domínguez García, N. (2007). Conectores discursivos en textos argumentativos breves. Madrid: Arco/Libros.

Estrada Arráez, A.; Benito Moreno, C. de (2016). Variación en las redes sociales: datos twilectales. RILI, 8 (28), 77-111.

Fuentes Rodríguez, C. (1987). Enlaces extraoracionales. Sevilla: Alfar.

Fuentes Rodríguez, C. (1993). Conectores pragmáticos. En Alcaide Lara, E., Ramos Márquez, M. M. y Salguero Lamillar, F. (Eds.), Estudios lingüísticos en torno a la palabra (pp. 71-104). Sevilla: Universidad de Sevilla.

Fuentes Rodríguez, C. (1998). Las construcciones adversativas. Madrid: Arco/Libros.

García Negroni, M M. (2000). El conector argumentativo incluso y la escalaridad en la lengua. En Sevilla Arroyo. F. y Alvar Ezquerra, C. (Eds.), Actas del XIII Congreso de la Asociación Internacional de Hispanistas (pp. 490-497). Madrid: Editorial Castalia, vol. 3.

Giammatteo, M.; Gubitosi, P.; Parini, A. (2017). El español en la red. Madrid/Frankfurt: Iberoamericana/Vervuert. DOI https://doi.org/10.31819/9783954877386

Gómez Torrego, L. (2001). La Gramática en Internet. En Nuevas fronteras del español: Lengua y escritura en Internet. Disponible en: http://congresosdelalengua.es/valladolid/ponencias/nuevas_fronteras_del_espanol/4_lengua_y_ escritura/gomez_l.htm [Consultado el 12-05-2020].

Koch, P.; Oesterreicher, W. (1990 [2007]). Lengua hablada en la Romania: español, francés, italiano. Madrid: Gredos.

Landone, E. (2009). Riflessioni sui marcatori del discorso nella scrittura digitale interattiva e asincrona. En Cocco, S., Pinna, A. y Varcasia, C. (Eds.) Corpora, discorso e stile (pp. 163-178). Roma: Aracne.

Landone, E. (2012). Discourse markers and politeness in a digital forum in Spanish. Journal of Pragmatics, vol. 44, n. 13, 1799-1820. DOI https://doi.org/10.1016/j.pragma.2012.09.001 
López Quero, S. (2007). Marcadores discursivos y cortesía en la conversación virtual en español. Language Design, 9, 93-112.

López Quero, S. (2010). Marcas gramaticales de la oralidad en los chats y foros de debate: incorporación de marcadores discursivos del español hablado. Oralia. Análisis del discurso oral, 13, 173-195.

López Quero, S. (2019). El marcador discursivo ahora con verba dicendi en Twitter. Círculo de lingüística aplicada a la comunicación, n. 77, 243-260. Disponible en: https://revistas.ucm.es/index.php/CLAC/article/view/63287 [Consultado el 22-05-2020]. DOI https://doi.org/10.5209/CLAC.63287

López Serena, A.; Borreguero Zuloaga, M. (2010). Los marcadores del discurso y la variación lengua hablada vs lengua escrita. En Loureda Lamas, Ó. y Acín Villa, E. (Eds.), Los estudios sobre marcadores del discurso, hoy (pp. 325-405). Madrid: Arco/Libros.

Loredo, R.; Picone, M. (2012). Los marcadores discursivos en Twitter: el uso de \#ponele como marca de ironía. En Cristófalo, A. (Eds.), Actas del V Congreso Internacional de Letras (pp. 1773-1779). Buenos Aires: Universidad de Buenos Aires.

Loureda Lamas, Ó.; Acín Villa, E. (Eds.) (2010). Los estudios sobre marcadores del discurso en español, hoy. Madrid: Arco/ Libros.

Mancera Rueda, A.; Pano Alamán, A. (2013). El español coloquial en las redes sociales. Madrid: Arco/Libros.

Martín Zorraquino, Ma A.; Portolés Lázaro, J. (1999). Los marcadores del discurso. En Bosque, I. y Demonte, V. (Dirs.), Gramática descriptiva de la lengua española (pp. 4051-4214). Madrid: Espasa, vol. 3.

Montolío Durán, E. (2001). Conectores de la lengua escrita. Barcelona: Ariel.

Padilla Herrada, $\mathrm{M}^{\mathrm{a}}$ S. (2016). Marcadores y partículas discursivas interactivas en el entorno político/periodístico de Twitter. Philologia Hispalensis, 30/1, 193-212. DOI https://doi.org/10.12795/PH.2016.i30.10

Pano Alamán, A. (2015). Aproximación a los marcadores del discurso en los comentarios de la prensa digital española y argentina. Revista del Instituto de Investigaciones lingüísticas y literarias hispanoamericanas, 20, 89-114.

Pano Alamán, A.; Mancera Rueda, A. (2014). La “conversación” en Twitter: las unidades discursivas y el uso de marcadores interactivos en los intercambios con parlamentarios españoles en esta red social. Estudios de Lingüistica del Español, 35 (1), 234-268.

Pons Bordería, S. (1998). Conexión y conectores. Estudio de su relación en el registro informal de la lengua. Valencia: Publicaciones de la Universidad de Valencia.

Porroche Ballesteros, M. (1996). Las llamadas conjunciones como elementos de conexión en el español conversacional: pues/pero. En Kotschi, T., Oesterreicher, W. y Zimmerman, K. (Eds.), El español hablado y la cultura oral en España e Hispanoamérica (pp. 71-94). Madrid/Frankfurt: Iberoamericana/Vervuert.

Portolés Lázaro, J. (1989). El conector argumentativo pues. Dicenda, 8, 117-133.

Portolés Lázaro, J. (1995). Diferencias gramaticales y pragmáticas entre los conectores discursivos "pero, sin embargo y no obstante". Boletín de la Real Academia Española, 75 (265), 231-270. 
Portolés Lázaro, J. (1998). Marcadores del discurso. Barcelona: Ariel.

Portolés Lázaro, J. (2010). Los marcadores del discurso y la estructura informativa. En Loureda, Ó. y Acín-Villa, E. (coords.), Los estudios sobre marcadores del discurso en español, hoy (pp. 281-326). Madrid: Arco Libros.

Sal Paz, J. (2007). Rasgos de oralidad en los foros de discusión de la prensa digital. El caso de La Gaceta On Line. En Granato de Grasso, L. (Ed.), Diálogo y contexto (pp. 555-570). La Plata: Universidad Nacional de La Plata.

Robles Ávila, S.; Moreno Ortiz, A. (Eds.) (2019). Comunicación mediada por ordenador. La lengua, el discurso y la imagen. Madrid: Cátedra. 
